\title{
An Assessment of Unused and Regular Use Medicines in Rural Households
}

\author{
Vineela Chadalavada, Lingamguntla Chelmi Kumar, Edururi Navya Sri Reddy, \\ Mandhapati Vaikunta Varma
}

Department of Pharmacy Practice, SIMS College of Pharmacy, Guntur, Andhra Pradesh, INDIA.

\begin{abstract}
Objectives: Medicines play a crucial role in today's modern lifestyle. It is a known fact that it would be difficult to find a house without medicines. The World health organisation reports that $50 \%$ of medicines fall under irrational drug use by humans and majority fail to consume them entirely and correctly. This condition may result in large amounts of leftover medication waste in the households which may be reused or misused, which tends to be dangerous. Our study objective is to find out the proportion of regular and unused medicines present in the households of a rural village in Andhra Pradesh State. Methods: It is a cross-sectional household survey done among 320 households in a rural area of Andhra Pradesh. Data was collected in pre-designed data collection form and analyzed using SPSS software version 16. Results: Among the surveyed households, 252 (78.7\%) have unused medication that and a mean of $6.3( \pm 1.5)$ drug products was found per family. The diseases commonly observed are, Diabetes 114(13.9\%), gastrointestinal diseases 112(13.6\%), respiratory diseases 104(12.68\%) and hypertension $66(8 \%)$. The stored drugs found in the households belonged mostly to five categories; Nonsteroidal anti-inflammatory drugs, antibiotics, proton pump inhibitors, antacids and antipyretics. Conclusion: The present study revealed that a significant proportion of rural households had stored unused medicines at home for reusing among family and friends and about none of them had safe storage; hence, is susceptible to various health hazards and accidental poisoning.
\end{abstract}

Key words: Household survey, Unused drugs, Irrational drug use, Left over medicines, Reuse of medicines, Unsafe drug use.

\section{INTRODUCTION}

In the most recent decades, drugs have had an extraordinary constructive outcome on the wellbeing of the people across the Globe, prompting decreased disease burden and mortality rate.

It is a known fact that the human race cannot survive without certain crucial elements like food, water and air. In future, we may likewise hear humankind's endurance decreases without medicines. This condition may be the result of anthropogenic impact on the environment and human races. Simultaneously, there is abundant proof that an enormous 'missed potential' exists given how medications are utilized: the correct medication does not generally arrive at the correct patient; roughly half of all patients neglect to take their medication effectively and by the capacity of the framework is not adequate to help the ideal utilization of prescriptions. ${ }^{1,2}$
In developing countries like India, the condition is regrettable with the need for strong drug policies. Medicines for the majority of clinical indications are easily accessible in the market without a legal prescription. This condition may make medication wastage, yet in addition wastage of economy. Above all, patients may experience unwanted effects of drugs when they are not properly prescribed, stored and used. There is a huge demand for creating awareness regarding the irrational use of medicines which can forestall the undesirable impacts. Self-medication is another issue, especially for over-the-counter medications which represent several drug-interactions and adverse drug reaction with lack of knowledge on drugs. ${ }^{3}$ With the present condition of irrational use, drugs like antibiotic demonstrated higher resistance and miss potential to fight with microorganisms. ${ }^{4}$
DOI: 10.5530/ijopp.14.3.37

Address for correspondence: Dr. Vineela Chadalavada Department of Pharmacy Practice, SIMS College of Pharmacy, Guntur-522001, Andhra Pradesh, INDIA. Phone no: +91-9866356275 Email Id: vineelach99@gmail. com

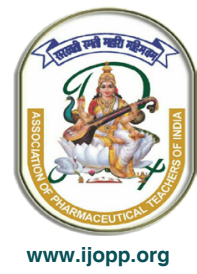


WHO along with other health care bodies are promoting responsible use of drugs for a healthy tomorrow?. The WHO defines rational medicine use as, patients receive the appropriate medicines, in doses required by their own individuals, for an adequate period of time and at the lowest cost both to them and the community. Irrational (inappropriate, improper, incorrect) use of medicines is when one or more of these conditions are not met. ${ }^{1}$ The WHO, in 2014, reported the situation of medication adherence accounts for $50 \%$ worldwide and the scenario is worse in developing and transitional countries. ${ }^{5}$

In many families, medications recommended by the doctors are not expended totally and are left unused and squandered. And in some cases, patients discontinue the prescribed drugs when the symptoms resolve. Such leftover drugs are stored for reuse in the future, often without consulting the physicians. This malpractice of wrongful self-medication or sharing of medicines among friends, families were exposing the community to potential health hazards. ${ }^{6}$ All such unused medicines expire or deteriorate turn as medicine wastage which tends to be disposed of in a proper way. ${ }^{7}$

A general, a definition of medication wastage stated by Abou-Auda HS. et al. that medication wastage refers to "any prescribed or purchased over the counter (OTC) drug product, that is never fully consumed. Factors for production of medical wastage may be massive uncontrolled sale of medication by the community pharmacies, poly-pharmacy and poor compliance of the patient. ${ }^{4}$

In India, very few studies were reported on unused drugs and medicine wastage with emphasis to rural communities. With such background, we have conducted the study with a primary objective of finding the number of unused drugs and regular use medicines in households of a rural community. Moreover, we also evaluated the cost spent on such drugs.

\section{MATERIALS AND METHODOLOGY}

Study Site: Our present study was planned and conducted in a rural village and our selection of the village was based on the convenience of the investigators. Hence we have selected Pedakakani village, which was mapped under rural Guntur city, Andhra Pradesh, South India.

Study Design: This is a community-based, nonexperimental, descriptive and cross-sectional study design was chosen as the means to investigate the type and extent of medicine usage and wastage among households in a rural area. The study was conducted during the months of January and February 2020 in the selected village.

Study population and sampling: The target population in this study was households/ families with all the age groups. The three investigators are trained in data collecting and approaching the households in their own language. From the census data, the total number of households in the selected village for the survey is 6256 (census 2011).

The estimated sample size necessary for this study was obtained utilizing the sample size equation given below. Where ' $\mathrm{p}$ ' was assumed to be $50 \%$, allowable error ' $\mathrm{e}$ ' was $5 \%$ and ' $z$ ' is the standard normal deviate with a value of 1.96. The sample size of 362 or more measurements/ surveys is necessary for the study to have a confidence level of $95 \%$ that the real value is within $\pm 5 \%$ of the measured/surveyed value.

$$
\text { Sample size }=\frac{\frac{z^{2} \times p(1-p)}{e^{2}}}{1+\left(\frac{z^{2} \times p(1-p)}{e^{2} N}\right)}
$$

Cluster random sampling technique was used for surveying households. However, the investigators have encountered many barriers, such as hesitation to share the information and non-availability of the respondents. With the great effort of educating the rural households, 320 respondents expressed willingness and have given concern for participation in the survey.

Initial ethical clearance was obtained from the institutional ethical committee present at SIMS college of pharmacy, Acharya Nagarjuna University, with a reference number; IHEC/SIMS/2019/031. This is a non-experimental surveillance study with minimal risk; however, written informed consent was obtained from any member of surveyed households.

Study tools: The methodology for the present study was developed from the WHO Manual on "How to investigate the use of medicines by consumers'.

Data collection forms are pre-designed with the referring the manual and taken approval from human ethical committee. Informed consent form used in the study was designed with reference to WHO format and approved by the Institutional ethical board.

Data collection form developed for the study consists of three parts;

- Socio-demographical details of households; Family size, age, gender, educational and social status.

Indian Journal of Pharmacy Practice, Vol 14, Issue 3, Jul-Sep, 2021 
- The pattern of drugs found in the households; Usage and unused drugs separated by pharmacological classification and mode of procurement.

- Checklist for storage and disposable; Expiry date, condition of dosage form, storage condition.

The investigators collected the data of drug use from the households by the door-to-door visit. Informed concern was taken from the responders willing to share their information before encountering the study questionnaire. The investigators used local language for obtaining accurate information from the respondents. The data from data collection forms were verified before entering into a validation form. Analysis of data was performed using SPSS version 16.0 software. Descriptive statistics (mean standard deviation [SD] and median for the continuous variables and frequency in percentage for the categorical variables), bivariate and multivariable logistic regression were used for data interpretation.

\section{RESULTS}

In the present study done at rural Guntur city, out of a total of 320 households expressed willingness to participate in the study with a mean family size of 3.83 \pm 1.05 . The average age of family members is $46.5 \pm$ 18.3 years, with $1.11 \pm 0.3$ patients in a family. Total family members included in the survey are 1226 , of the $41.6 \%$ are male and $58.4 \%$ are female. Most of them have middle income (49.3\%) to lower-income in their families (45.6\%). Out of a total of 320 households, 252(78.7\%) bear's unused medicines (Table 1).

Figure 1 depicts the categorization of unused drugs found during the household survey. Total 1948 medicines are found in 320 households of them, 1358 (69.7\%) are Prescription drugs, 594 (30.4\%) are Over the counter drugs/Self-medication, $744(37.7 \%)$ are un-used medication and 264(13.5\%) Expired drugs found.

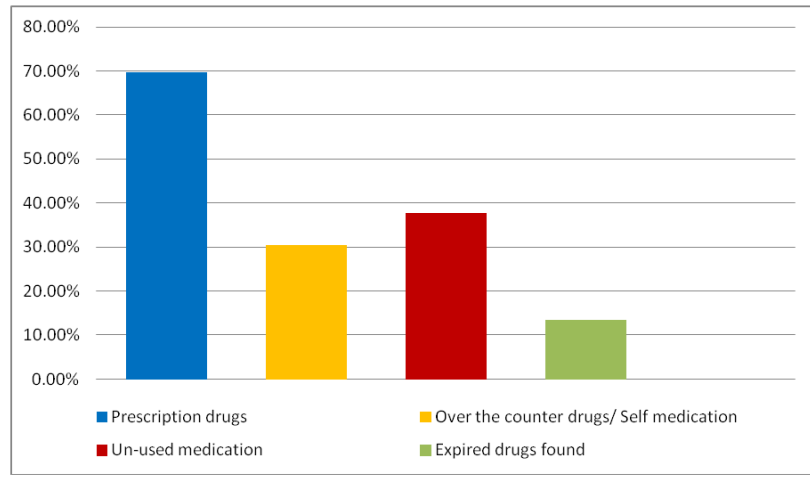

Figure 1: The categorization of drugs found in the household survey.
Majority of the detected patients are diabetes (13.9\%), gastrointestinal complaints $(13.6 \%)$, respiratory diseases $(12.68 \%)$ and allergies $(7.8 \%)$ (Table 2). Drugs found in the households are classified in Table 3. Antimicrobials account for $11.1 \%$ and a significant factor to be considered is $48.1 \%$ of total antimicrobials obtained during the survey are found unused.

Unused drugs are detailed and depicted in Table 4. Vitamins and mineral supplements $(48.3 \%)$ and antitussives (97\%) are left majorly unused in many households. Along with antimicrobials, Analgesics $(9.9 \%)$, Antihistamine (10.7\%), drugs for gastrointestinal disturbances (11.8\%) and Anti-pyretic (9.6\%) are mostly left unused and saved for the future use.

\section{DISCUSSION}

Among the surveyed 320 households, almost all the families have one or more medicines stored for regular use or occasional use. Of them, $252(78.7 \%)$ had unused medicines that are stored in storage containers which are unsafe and in reach of children. In a similar study at West Bengal reported 61.1\% unused medication found from 143 households. ${ }^{6}$ In the present study, a mean of $6.3( \pm 1.5)$ drug products was found per family. Whereas in Jordan, a mean of $6.5( \pm 2.5)$ drugs are found per household, most of them stored in the refrigerator. ${ }^{9}$ Whereas in Saudi Arabia, $8( \pm 4.3)$ drugs are found. ${ }^{4}$ In the United Kingdom, $99 \%$ of families have more than one medication, with a mean of 10.3 drugs per family

\begin{tabular}{|c|c|c|}
\hline Variable & \multicolumn{2}{|c|}{ Values } \\
\hline $\begin{array}{l}\text { Total No. families participated in } \\
\text { the survey }\end{array}$ & \multicolumn{2}{|c|}{320} \\
\hline Mean family size & \multicolumn{2}{|c|}{$3.83 \pm 1.05$} \\
\hline Median family size & \multicolumn{2}{|c|}{4} \\
\hline Average age of family members & \multicolumn{2}{|c|}{$46.5 \pm 18.3$} \\
\hline Average patients in a family & \multicolumn{2}{|c|}{$1.11 \pm 0.347$} \\
\hline \multirow[t]{3}{*}{$\begin{array}{l}\text { Average No. of medicines found } \\
\text { in a family }\end{array}$} & \multicolumn{2}{|c|}{$6.3 \pm 1.5$} \\
\hline & Total & Percentage \\
\hline & \multicolumn{2}{|c|}{ Gender } \\
\hline Male & 512 & $41.6 \%$ \\
\hline Female & 716 & $58.4 \%$ \\
\hline Total family members & 1226 & \\
\hline \multicolumn{3}{|l|}{ Economical status } \\
\hline Higher income & 16 & $5.0 \%$ \\
\hline Middle Income & 158 & $49.3 \%$ \\
\hline Lower Income & 146 & $45.6 \%$ \\
\hline Households with Unused drugs & 252 & $78.7 \%$ \\
\hline
\end{tabular}


and most of them stored in the kitchen. ${ }^{10}$ The situation in India is found better than in other countries. The reason may be, in India, only lower economic class people have government health insurance coverage and the rest of

\begin{tabular}{|c|c|c|}
\hline Clinical condition & Total & Percentage \\
\hline Diabetes & $114^{* * *}$ & $13.9 \%$ \\
\hline Hypertension & 66 & $8 \%$ \\
\hline Thyroid disorders & 46 & $5.6 \%$ \\
\hline Gastro intestinal diseases & $112^{* *}$ & $13.6 \%$ \\
\hline Cardio vascular disease & 58 & $7 \%$ \\
\hline Central nervous diseases & 38 & $4.6 \%$ \\
\hline Respiratory disease & $104^{*}$ & $12.68 \%$ \\
\hline Allergies & 64 & $7.8 \%$ \\
\hline Joint pains & 36 & $4.39 \%$ \\
\hline Diarrhea & 20 & $2.4 \%$ \\
\hline Fever & 36 & $4.63 \%$ \\
\hline Head ache & 22 & $2.6 \%$ \\
\hline Other Infections & 30 & $3.6 \%$ \\
\hline Others & 72 & $8.78 \%$ \\
\hline Total & 818 & \\
\hline
\end{tabular}

population has to spend money on their own for health care unless they have any insurance coverage. Whereas in other developed countries, health care economics is covered by local government and hence they are free to receive the right quantity of drugs. Atinafu $e t$ al. found a higher proportion $(89.1 \%)$ of unused medicines in their study participants who were from a rural background similar to our study subjects. ${ }^{11}$ Studies done by Aditya in Chandigarh, $95 \%$ of participants had stored left-over drugs may be due to the medical background of the participants in the latter. ${ }^{12}$

In our present study, the four clinical indications for which the households were using medications on regular intervals are; Diabetes (13.9\%), gastrointestinal diseases $(13.6 \%)$, respiratory diseases $(12.68 \%)$ and hypertension $(8 \%)$. The stored drugs found in the households belonged mostly to five categories; NSAIDS (30.4\%), antibiotics $(29.8 \%)$, proton pump inhibitors $(18.9 \%)$, antacids $(15.5 \%)$ and antipyretics $(14.3 \%)$. The results obtained in our present study were contrasted to results from various parts of India and the world as well. In a similar study at West Bengal CNS agents (25.2\%), antibiotics $(17.4 \%)$, musculoskeletal agents $(13.4 \%)$ and respiratory agents $(12.3 \%)$ are majorly found. ${ }^{6}$ Our results are contrasted to similar studies at Saudi and Iraq in Saudi, respiratory agents $(16.8 \%)$, CNS agents $(16.4 \%)$ and

\begin{tabular}{ccccc}
\multicolumn{5}{l}{ Table 3: Categorization of drugs found in the households. } \\
Drug Category & $\begin{array}{c}\text { Frequency } \\
\text { (Percentage) }\end{array}$ & Rx & OTC/SM & Unused drugs \\
\hline Antimicrobials & $108(11.1 \%)$ & $80(74.1 \%)$ & $28(25.9 \%)$ & $52(48.1 \%)$ \\
Analgesic & $46(4.7 \%)$ & $15(32.6 \%)$ & $31(67.3 \%)$ & $37(80.4 \%)$ \\
CNS & $36(3.7 \%)$ & $34(94.4 \%)$ & $02(6.5 \%)$ & $03(8.3 \%)$ \\
CVS & $80(8.2 \%)$ & $80(100 \%)$ & -- & $02(2.5 \%)$ \\
Dermal & $17(1.7 \%)$ & $06(35.2 \%)$ & $11(64.7 \%)$ & $14(82.3 \%)$ \\
Diabetic & $106(10.9 \%)$ & $94(88.6 \%)$ & $12(11.3 \%)$ & $02(1.8 \%)$ \\
Diarrheal & $10(1.0 \%)$ & $4(40 \%)$ & $6(60 \%)$ & $10(100 \%)$ \\
GIT & $103(10.6 \%)$ & $44(42.7 \%)$ & $59(57.2 \%)$ & $44(42.7 \%)$ \\
Antihistamine & $50(5.1 \%)$ & $08(16 \%)$ & $42(84 \%)$ & $45(90 \%)$ \\
HTN & $96(9.9 \%)$ & $96(100 \%)$ & -- & $07(7.2 \%)$ \\
Atilipid & $37(3.8 \%)$ & $37(100 \%)$ & -- & 0 \\
NSAID & $28(2.9 \%)$ & $14(50 \%)$ & $14(50 \%)$ & $15(53.5 \%)$ \\
Opiod & $12(1.2 \%)$ & $06(50 \%)$ & $06(50 \%)$ & 08 \\
Pyretic & $42(4.3 \%)$ & $6(14.2 \%)$ & $36(85.7 \%)$ & $36(85.7 \%)$ \\
Respiratory & $21(2.2 \%)$ & $21(100 \%)$ & -- & $2(9.5 \%)$ \\
Sterod & $11(1.1 \%)$ & $11(100 \%)$ & -- & $2(18.1 \%)$ \\
Thyroid & $25(2.6 \%)$ & $25(100 \%)$ & -- & 04 \\
Tussives & $34(3.5 \%)$ & $08(23.5 \%)$ & $26(76.4 \%)$ & $33(97 \%)$ \\
Vit_Mineral & $89(9.1 \%)$ & $82(92.1 \%)$ & $07(7.8 \%)$ & $43(48.3 \%)$ \\
Others & $30(3.08 \%)$ & $26(86.6 \%)$ & $04(13.3 \%)$ & $17(56.6 \%)$ \\
Total & $974(100 \%)$ & & & \\
\hline & & & & \\
\hline
\end{tabular}


Table 4: Significant portions of unused drug classes found in the rural households: Drug Category

\begin{tabular}{ccc} 
& Unused drugs & Percentage \\
\hline Antimicrobials & 52 & $13.9 \%$ \\
Analgesic & 37 & $9.9 \%$ \\
Dermal & 14 & $3.7 \%$ \\
Diarrheal & 10 & $2.6 \%$ \\
GIT & 44 & $11.8 \%$ \\
Antihistamine & 45 & $10.7 \%$ \\
NSAID & 15 & $4 \%$ \\
Opiod & 08 & \\
Anti-Pyretic & 36 & $9.6 \%$ \\
Tussives & 33 & $97 \%$ \\
Vit_Mineral & 43 & $48.3 \%$ \\
Others & 17 & $56.6 \%$ \\
Total & 372 & \\
\hline
\end{tabular}

antibiotics account for the majority of drugs found in the households, however at Iraq CNS agents and antiinfectives are the medication available at household. The medicine items were procured from medical personnel or OTC.

The most common reason for unused drugs present at home might be "discontinuation of the given drugs after the recovery from illnesses" before the prescribed duration. Plan to reuse the medicines in the near future was the predominant reason for storing and not disposing of in the trash.

In India, CNS agents are scheduled under Drugs and cosmetic act 1945, Schedule H1; the drugs obtained only on prescription. This might be the reason for variation in results obtained in our study in south India. Nevertheless, surprisingly, in all the studies, it was observed that antibiotics are one among highly used medication among households which may contribute to threat of AMR. The left-over antibiotics may be reused by the family, which may result in side effects or adverse drug events. Similarly, if they are disposed of in the garbage without proper disposable practices, the environment may get polluted with drug-resistant micro-organisms.

\section{CONCLUSION}

The present study at a rural setting has its strength in finding out reasons for left-over medications. Reusing was found the major reason and none of them followed safe storage hence susceptible to accidental poisoning and health hazards.
Drug take-back initiatives programs and policies should be developed and encouraged by trained health care workers. However, our present study has certain limitations, i.e., chances of recall bias in the case of selfreported information and the small sample size, hence broader conceptual framework and large sample size are warranted in the future to address this untouched issue of unused medication.

\section{ACKNOWLEDGEMENT}

We thank the study participants of Pedakakani village for sharing their drug use information which made this study possible with productive outcomes.

\section{CONFLICT OF INTEREST}

The authors declare no conflict of interest.

\section{ABBREVIATIONS}

WHO: World health organization; OTC: Over the counter; ICH GCP: International Conference on Harmonisation-Good Clinical Practice; SD: standard deviation; NSAIDS: Non-steroidal anti-inflammatory drugs; AMR: Antimicrobial resistance.

\section{SUMMARY}

In our investigation we have found a significant portion of left over medicines in the households stored in unsafe method and majority of them are meant for reusing among family and friends. This practice may lead to various health hazards and accidental poisoning. Awareness should be developed among people regarding storage and disposal of leftover medication in the households.

\section{REFERENCES}

1. World Health Organization. WHO policy perspectives in medicines: Promoting rational use of medicine: core components. WHO Report. 2012.

2. Prabhu VA, Naik V, Doddapaneni S, Mateti UV, Nagappa AN. A survey on medicines safety and usage in community pharmacy. J Basic Clin Pharm. 2013;5(1):24-5

3. Balamurugan E, Ganesh K. Prevalence and pattern of self medication use in coastal regions of South India. Br J Med Pract. 2011;4(3):a428.

4. Abou-Auda HS. An economic assessment of the extent of medication use and wastage among families in Saudi Arabia and Arabian Gulf Countries. Clin Ther. 2003;25(4):1276-92.

5. Holloway KA, Henry D. WHO essential medicines policies and use in developing and transitional countries: An analysis of reported policy implementation and medicines use surveys. PLoS Med. 2014 16;11(9):e1001724.

6. Maharana S, Paul B, Dasgupta A, Garg S. Storage, reuse and disposal of unused medications: A cross-sectional study among rural households of Singur, West Bengal. International Journal of Medical Science and Public Health. 2017;6(7):1185-9.

7. Gray, R. Guidelines for Safe Disposal of Unwanted Pharmaceuticals in and after Emergencies; World Health Organization: Geneva, Switzerland. 1999; 31. 
8. World Health Organization and University of Amsterdam. How to investigate the use of medicines by consumers. 2004;20-36.

9. Al-Azzam S, Khader Y, Rawashdeh S, Hijazi S. An assessment of the Extent of Medication Wastage among Families in Jordan. Jordan $\mathrm{J}$ Pharm Sci. 2012;5(1):65-73.

10. Laurence DR, Bennet PN. Topics in drug therapy, Clinical Pharmacology. ELBS, Churchill Livingstone, Singapore. 1987.
11. Atinafu T, Takele A, Kassie A, Yehualaw A, Tesfaw G, Desseno T, et al. Unused medications disposal practice: The case of patients visiting university of gondar specialized teaching hospital, Gondar, Ethiopia. Int J Pharm Sci Res. 2014;5(12):999-1005.

12. Aditya S. Safe medication disposal: Need to sensitize undergraduate students. Int J Pharm Life Sci. 2013;4(3):2475-80. 